Biacitica

\section{RETIRADA DA VENTILAÇÃO MECÂNICA NA ANTECIPAÇÄO DA MORTE EM UNIDADE DE TERAPIA INTENSIVA}

Diversos estudos demonstram que, em pacientes terminais na unidade de terapia intensiva (UTI), a morte ocorre após a omissão ou a suspensão do suporte de vida. $A$ ventilação mecânica (VM) é o suporte de vida mais avançado na UTI e a sua suspensão é o ato mais freqüente após a decisão de antecipação de morte.

Os autores estudaram adultos em VMem I5 UTIs a fim de definir quais os critérios clínicos associados à suspensão da VM. O total de pacientes em VM foi de 85I, I 46 (I7,2\%) faleceram em uso da VM; em I66 (19,5\%) foi suspenso este suporte de vida, e após a retirada, I 45 pacientes $(87,3 \%)$ morreram na UTI e I5 (9\%) morreram no hospital.

Nestes 166 pacientes, a presença da ordem de não ressuscitar, assim como um menor uso de drogas vasoativas, foi estatisticamente significante quando comparado ao outro grupo. Após análise de multivariáveis os critérios associados à retirada da VM foram: a) uso de inotrópicos e vasopressores; b) a previsão médica de uma sobrevida menor do que $10 \%$; c) a previsão médica de um dano grave da função cognitiva que o impediria de ter alta; d) a percepção do médico dos pacientes que preferiam morrer fora da VM.

\section{Comentário}

É compreensível que, do ponto de vista ético, a morte no paciente terminal seja um evento natural e até muitas vezes desejado, estando embasado nos princípios bioéticos da não-maleficência, da beneficência, do respeito à autonomia e da justiça. Porém, uma vez que se mantenha 0 suporte vital artificialmente, a não-adoção de medidas de ressuscitação não é capaz por si só, de impedir ou limitar o processo terapêutico e toda a terapêutica, curativa é mantida até que o óbito ocorra. Este tratamento, por vezes excessivo, que se instala no doente nessa fase terminal, permitindo o seu prolongamento além do "natural", traz ônus para o paciente, para a família e para a sociedade.
Desse modo, quando ocorre a inversão de expectativas de curar para cuidar, a omissão e a suspensão do suporte vital adquirem um papel preponderante e coerente com esse novo objetivo. Assim, entende-se porque a freqüência dessas condutas vem aumentando nas UTIs, proporcionalmente, com a melhoria dos ventiladores, das terapias de substituição renal, das novas drogas vasopressoras que sustentam a vida artificialmente de modo eficaz, nada desejado para o doente em estágio final.

$E$ interessante observar que este estudo demonstra que a percepção do médico em relação à função cognitiva, do prognóstico $<10 \%$ de sobrevida), e do desejo do paciente em relação a não usar a VM foram os fatores preditivos independentes determinantes da conduta. Ou seja, fatores que incluem a subjetividade e a qualidade de vida, anteriormente pouco aceitos nas discussões médicas que buscam índices de gravidade, de risco de morte e disfunção de múltiplos órgãos para apoiar tais condutas.

\section{LARA Torreão}

Referências

I. CookD, RockerG, Marshall],SjokvistP,Dodek $P$, Griffith $L$, et al. Withdrawal of mechanical ventilation in antecipation of death in the intensive care unit. N Engl J Med 2003, 349: I | 23-32.

2. Jayers RL, Zimmerman JE, Wagner DP, Draper,EA, Knaus WA. Do-not-resuscitate orders in intensive care units: current practices and recent changes. JAMA 1993, 270:2213-7. 3. Nelson JE, Danis M. End-of-life care in the intensive care unit: Where are we now? Crit Care Med 200I, 29:2-9.

4. Königova R. Do-not-resuscitate orders and withheld or withdrawn treatment. Acta Chir Plast 1996; 38:73-7.

5. Manara, AR; Pittman, JAL.; Braddon, FEM.; Reasons for withdrawing treatment in patients receiving intensive care. Anaesthesia, v.53, p. 523-8, 1998.

\section{Clinica Ciriorgica \\ ENDOMETRIOSE DA PAREDE ABDOMINAL}

Na prática cirúrgica diária é comum recebermos doentes com queixas de tumorações na parede abdominal, geralmente após procedimentos cirúrgicos. Freqüentemente estão relacionadas a hérnias incisionais ou granulomas de corpo estranho (fios cirúrgicos em geral). Mas, algumas vezes, as queixas vêm relacionadas ao ciclo menstrual e após procedimentos obstétricos (cesarianas) ou ginecológicos por via abdominal.

Em face desta situação, Ceniceros Franco et al. fizeram um estudo no Departamento de Ginecologia e Obstetrícia do Hospital American British Cowdray (México), assim como um levantamento de literatura a respeito da endometriose da parede abdominal. Verificou-se que o diagnóstico está cada vez mais presente, sendo o diagnóstico de endometriose nas diversas apresentações feito em cerca de $15 \%$ das mulheres em idade fértil.

Além da apresentação na parede abdominal, já foi descrito apresentações na pleura, pulmões, pele, baço, vesícula biliar, estômago, peritôneo livre, intestinos e rins.

O diagnóstico de imagem (USG, CT, RM) nem sempreé preciso (não há especificidade) e o diagnóstico de confirmação é feito pelo estudo anatomopatológico (biópsia por agulha ou excisional).

Ao tratamento clínico medicamentoso de suporteimpõem-sea excisão completa da massa tumoral assim como as lesões recorrentes.

\section{Comentário}

Este trabalho, à primeira vista simples, mostra uma preocupação dos autores com a saúde da população de sua comunidade, pois nem só de grandes doenças e tratamentos hiperespecializados vive a medicina, podendo e devendo sempre que possível alertar a toda a classe médica situações usuais, mas de grande relevância.

Darcy lisbão Moreira de Carvalho Maria Filomena Teixeira de Carvalho

Referência

Ceniceros Franco G, Cruz Minoli V, Díaz ArgüelloD, Muñuzuri IñiguezF. Endometriosis de pared abdominal. Revisión de la literature. Ginecol Obstet Mex 2002; 70:619-2I.

\section{Emergência e Medicina Tutensiva PROGRAMAS DE APLICAÇÃO MÉDICA PARA PALMTOPS}

Atualmente, mais de um quarto dos médicos canadenses possuem um palmtop e esse número deverá dobrar nos próximos dois 